\title{
Plastic waste management: is circular economy really the best solution?
}

\author{
Johann Fellner ${ }^{1}\left[\mathbb{C}^{\circ}\right.$ Paul H. Brunner ${ }^{1}$
}

Received: 13 November 2021 / Accepted: 13 December 2021 / Published online: 22 December 2021

๑) Springer Japan KK, part of Springer Nature 2021

Nowadays, the concept of Circular Economy (CE) is omnipresent; even the name of the journal you are holding in your hands gives evidence of this fact. It is widely acknowledged that a $\mathrm{CE}$ is instrumental for reaching the objectives of waste management, namely resource conservation and environmental protection. What is less often discussed is that a CE is not a goal per se, but rather a means of attaining the two objectives mentioned above. The distinction between objectives and means is of utmost importance, and not just an academic exercise. It is crucial for the success or failure of any waste management strategy. In our editorial, we would like to shed light on this point by discussing the limits of a CE strategy for plastic materials.

Plastics consumption has increased tremendously in recent decades. In 1990, the global production of plastic materials amounted to 100 Mio tons; this figure increased fourfold to almost 400 Mio tons in 2020. Only a minor fraction of these plastic flows is currently recycled. Even in advanced economies like the European Union, the overall recycling rates of plastics are low: the production of recycling plastics in the $\mathrm{EU}(+\mathrm{UK})$ amounts to about 5.5 Mio tons/year which is less than $10 \%$ of the 60 Mio tons of primary plastics produced in Europe [1,2]. Much material cycling is downcycling of mixed plastics with associated recycling of organic and inorganic additives and pollutants.

Waste plastics consist of single as well as mixed polymers and comprise between 5 and 30\% of non-polymeric materials. These additives are necessary for reasons of polymerization (e.g., catalysts) and for the maintenance of plastic properties (UV stability, resistance to fire and microbial degradation, etc.). During recycling, they will either be transferred to secondary plastic products or, if hazardous, must be removed from the cycle. The term hazardous applies

Johann Fellner

johann.fellner@tuwien.ac.at

1 Institute for Water Quality and Resource Management, TU Wien, Karlsplatz 13/226, 1040 Vienna, Austria to humans, the environment, recycling processes as well as the quality of recycling products. Many, in particular legacy additives found in plastic, consist of heavy metals and persistent organic pollutants. Some are highly toxic and hazardous. Thus, the large-scale problem of detection, separation, and safe disposal of such substances must be solved before sustainable plastics recycling can take place. Several studies have shown that toxic additives (heavy metals, and POPs such as brominated flame retardants, phthalates) can been found in a broad range of products from children's toys to coffee cups made from recycled plastics [3-5]. Moreover, a non-negligible amount of marine and terrestrial plastic litter pollutes the environment, with harmful effects, particularly on oceans.

At present, two main drivers promote plastics recycling: 1. Economic benefits. This applies, on the one hand, to the recycling of relatively uniform production and consumption wastes. On the other hand, it is also true for plastic recycling in emerging economies with low collection and sorting costs, and a lack of quality standards for recycling products. 2. Regulations: post-consumer plastic waste recycling in affluent countries is generally driven by regulations. These regulations typically focus on single waste streams (e.g., packaging plastics, glass bottles, and cardboard). Within these waste streams, low hanging fruit such as PET bottles are typically harvested/recycled at the highest rate. However, even in countries with advanced regulations and sophisticated collection, sorting and recycling, the actual recycling rate of plastic is still low: for instance, it is estimated that less than $40 \%$ of PET bottles in the EU are recycled into secondary PET.

For other plastics used in goods with a long lifespan (such as water and wastewater pipes, window frames, floor liners, insulation of cables, and the like), a significant amount accumulates in the anthropogenic stock. Based on figures of Plastics Europe, it is estimated that the plastic stock in the EU increases annually by more than 20 Mio tons, or $30 \%$ of overall plastics consumption. Many plastic goods in 
old stocks hold legacy pollutants that are, in part, regulated and banned today. We need to find solutions for their final disposal. Recycling will only be possible if the hazardous substances can be removed from plastic waste. This is associated with excessive costs and is sometimes technically not possible. Thus, recycling is not a proper solution for those plastic wastes containing hazardous substances.

The EU CE agenda aims at significantly increasing plastic recycling, e.g., for packaging from presently $22.5 \%$ to $55 \%$ in the future. To fulfill this goal, recycling costs will significantly increase: today, at comparatively low recycling rates, the costs for plastic waste recycling, including separate collection, sorting, and recycling, amount to over 1200 Euro per ton of recycled plastic packaging. At higher recycling rates, these costs will necessarily increase, in part because the required chemical recycling is more cost intensive than the mechanical recycling currently applied. At the same time, the environmental benefits are limited: compared to the production of virgin plastics, about 1.2 tons of $\mathrm{CO}_{2}$ are saved for each ton of mechanically recycled packaging plastics. Hence, $\mathrm{CO}_{2}$ reduction costs via plastic recycling are in the range of 1,000 Euro per ton of $\mathrm{CO}_{2}$. In addition, potentially polluting substances are kept within the economy and accumulate in the stock, which must be treated in future.

Higher recycling rates are expected to have three major effects: first, the quality of recycled plastic is likely to be reduced if higher quantities are to be recycled because the low hanging fruit—uniform and "clean" plastic wastes—will have already been harvested. Second, the costs for plastics recycling will increase since the low hanging fruit mentioned, such as PET bottles, will have likewise already been harvested [6]. Third, the specific $\mathrm{CO}_{2}$ reductions induced by plastics recycling will become smaller [7]. This statement applies to an even greater extent if more and more plastics are chemically and not mechanically recycled in the future.

To promote informed decision making about optimum recycling quotas for plastic wastes, it is important to answer the following critical questions: does a proposed CE measure contradict the goals of waste management (resource conservation and environmental protection)? Are other waste management options more cost-effective in reaching these goals?

By way of example, let us consider an alternative path for plastics waste management using existing infrastructure for waste collection and treatment. In Europe, around 500 state-of-the-art WTE plants are in operation, turning about 100 million tons of municipal solid waste into heat and electricity and, in part, into useful materials as well. If these plants are upgraded with Carbon Capture Technology, the thermal utilization of plastics will cost about 500 Euro per ton of plastics (about 300 Euro for capturing $\mathrm{CO}_{2}$ emitted from plastics incineration and 200 Euro for the incineration of 1 ton of plastics). Hence, this technology is significantly cheaper than plastic recycling-by at least a factor of two.
Thermal utilization of plastic wastes applying carbon capture (capturing $90 \%$ of the emitted $\mathrm{CO}_{2}$ via chemical absorption) reduces the $\mathrm{CO}_{2}$ by 1 ton per ton of plastic utilized in comparison to heat production via natural gas. The latter can be regarded as a marginal technology for the production of heat and electricity in most affluent countries. Thus, $\mathrm{CO}_{2}$ savings via thermal utilization and carbon capture $(500 € /$ ton $\mathrm{CO}_{2}$ ) are accomplished for less than half of the costs in comparison to plastics recycling. Furthermore, thermal utilization destroys toxic organic substances in plastic wastes at a very high destruction rate ( $>99.9 \%)$. Inorganic pollutants can be either concentrated and reused or eliminated, immobilized and disposed of in secure landfills.

In the future, it may well be that $\mathrm{CO}_{2}$ from WTE can be recovered and used as a new feedstock. Such a carbon capture and utilization strategy still needs substantial technological development before implementation. However, if economically successful it would have many benefits such as much smaller requirements for land. The establishment of common rules for GHG emissions reduction could boost such a strategy.

In conclusion, we are convinced that for a large fraction of plastic wastes, thermal utilization with carbon capture is a more sustainable solution than recycling: it fulfills the goals of waste management better, leads to more environmental benefits (less emissions of $\mathrm{CO}_{2}$ equiv. and hazardous substances), reduces the stock of legacy plastics in our society and reduces the burden on consumers with respect to waste separation. In addition, it is much more cost-effective than $\mathrm{CE}$ measures that are less user-friendly.

$\mathrm{CE}$ is a valuable and appropriate strategy for resource and waste management. However, the example of plastic wastes shows in a paradigmatic way that to implement the CE strategy on a large scale, thorough and impartial individual assessments are required. It is crucial to bear in mind which measures lead to the best fulfillment of the goals at the least cost. Moreover,- - from a waste management point of view-it is important to remember that the main goals of waste management are not recycling, but rather the protection of humans and the environment as well as the conservation of resources into the future.

\section{References}

1. Plastics Europe (2020) Plastics - the facts 2020. An analysis of European plastics production, demand and waste data. Plastics Europe, Brussels, p 64

2. Plastics Recyclers Europe (2020) Report on plastics recycling statistics. Plastics Recyclers Europe, Brussels, p 6

3. Chen S-J, Ma Y-J, Wang J, Chen D, Luo X-J, Mai B-X (2009) Brominated flame retardants in children's toys: concentration, 
composition, and children's exposure and risk assessment. Environ Sci Technol 43(11):4200-4206

4. Ionas AC, Dirtu AC, Anthonissen T, Neels H, Covaci A (2014) Downsides of the recycling process: harmful organic chemicals in children's toys. Environ Int 65:54-62

5. Lee J, Pedersen AB, Thomsen M (2014) The influence of resource strategies on childhood phthalate exposure-the role of REACH in a zero waste society. Environ Int 73:312-322

6. Van Eygen E, Laner D, Fellner J (2018) Circular economy of plastic packaging: current practice and perspectives in Austria. Waste Manag 72:55-64
7. Van Eygen E, Laner D, Fellner J (2018) Integrating high-resolution material flow data into the environmental assessment of waste management system scenarios: the case of plastic packaging in Austria. Environ Sci Technol 52(19):10934-10945

Publisher's Note Springer Nature remains neutral with regard to jurisdictional claims in published maps and institutional affiliations. 